\author{
Amy J. Swain and Christian C. Evans \\ Physical Therapy Program, Midwestern University, \\ College of Health Sciences, 555 31st Street, AH 340E, \\ Downers Grove, IL 60515, USA
}

Dates: Received: 24 April, 2014; Accepted: 01 July, 2014; Published: 03 July, 2014

*Corresponding author: Christian C. Evans, Physical Therapy Program, Midwestern University, College of Health Sciences, 555 31st Street, AH 340E, Downers Grove, IL 60515, USA, Tel: (630) 515-7249; E-mail: cevans@midwestern.edu www.peertechz.com

ISSN: 2455-5282

\section{Case Report \\ The Effectiveness of a Home Exercise Program for a Young Athlete with Schmorl's Nodes: A Case Report}

\section{Introduction}

Soccer is one of the most popular sports among adolescent females [1]. Studies have shown that younger adolescent female soccer players (less than age 15) are at higher risk for injury than older adolescents (ages 15-19) [1]. A majority of soccer-related injuries among adolescent females are traumatic in origin, such as ankle sprains, anterior-cruciate ligament sprains, and muscle strains $[1,2]$. Over-use injuries among adolescent female soccer players include strains, tendinopathies, stress fractures, and low back pain [1,2].

Low back pain (LBP) is a common musculoskeletal condition in young athletes that should be taken seriously $[2,3]$. Low back pain is estimated to occur among $10 \%$ to $15 \%$ of young athletes [3]. It is often associated with sports that involve repetitive lumbar extension, flexion, and rotation, such as gymnastics, dance, and soccer. The most common source of LBP among young athletes are pars interatraticularis injuries, such as spondylolysis or spondylolisthesis, which occur in approximately $47 \%$ of young athletes with LBP [2]. Other causes of LBP include disc-related pathologies (11\%) and strains [2]. Adolescents are at greater risk for back injury because, during periods of rapid grown, muscles and ligaments are often unable to keep pace with the rate of bone growth, causing muscle imbalances and decreased spinal stability [2]. Articular cartilage and secondary ossification centers in the skeleton are particularly vulnerable to injury in young athletes because they have a decreased ability to transfer and absorb imposed forces [2]. Additional risk factors for LBP among young athletes include abdominal weakness, hamstring tightness, increased femoral anteversion, genu recurvatum, and increased thoracic kypohsis, which all increase lumbar lordosis and place increased stress on the lumbar spine [2]. LBP can affect participation among adolescents and has been shown to decrease quality of life, increase use of medications, and contribute to absence from school [3].

Approximately $10 \%$ of chronic lumbar spine injuries are of discogenic origin [4]. During the development of the spine, the nucleus pulposus is relatively more hydrophilic than that of an adult and distributes forces more centrally [5]. In periods of rapid growth, the vertebral body grows at its ossification site in the vertebral end plate. This end plate is composed of hyaline cartilage, lies just adjacent to the nucleus pulposus, and is often very weak. Thus, the combination of a centrally distributed force of the nucleus pulposus with the weak vertebral end plate often results in endplate disc herniations, or 
Schmorl's nodes [5]. Endplate disc herniations most often occur at the lumbothoracic junction. Patients with endplate disc herniations most often present with a sudden onset of acute LBP that is centrally located [4]. Further strain on the disc can cause inflammation, which may irritate the posterior longitudinal ligament, chemosensative nerve endings, and dura mater. However, nerve root involvement is rare in patients with Schmorl's nodes because the herniation is more centrally located. Pain is increased with prolonged sitting, coughing, and sneezing; it is often relieved by changing positions and by sleeping on one's side [4].

Typical treatment for Schmorl's nodes includes physical therapy and oral non-steroidal anti-inflammatories [2]. Physical therapy should include dynamic strengthening and core stability exercises. However, few studies have described the physical therapy management of LBP in young athletes with Schmorl's nodes. The purpose of this case report is to describe the treatment for a young athlete with Schmorl's nodes causing LBP and lower extremity (LE) weakness.

\section{Case Description}

\section{Patient history}

The patient was a 12-year-old female soccer player with a history of insidious thoracic and lumbar back pain that began 18 months prior to her initial physical therapy evaluation. At that time, the patient was seen by her primary care physician and referred to a specialist. She then received radiographs, magnetic resonance imaging, and a bone scan of the lumbar and thoracic spine. Testing revealed the presence of Schmorl's nodes in the lumbar region. After medical diagnoses, the patient received physical therapy at another location to address her back pain. She discontinued physical therapy after one month secondary to improvement in symptoms. Sixteen months later the patient was referred back to physical therapy secondary to an increase in symptoms in her lumbar spine.

Upon initial evaluation at her second round of physical therapy, the patient reported pain in her lower back that was greatest with prolonged sitting, transitioning from sitting to standing, running, and playing soccer. She described her pain as dull and achy with sitting and occasionally sharp with transitioning from sitting to standing and with running. She reported taking ibuprofen and acetaminophen as well as using heat on her back, as needed, to manage her pain. The patient's past medical history was significant for headaches, asthma, and a tibial fracture. Aside from the above history, the review of systems was noncontributory for the cardiovascular, pulmonary, gastrointestinal, genitourinary, and endocrine systems.

Upon initial examination, the patient presented with kyphotic thoracic posture, forward head positioning, anterior pelvic tilt, increased tone and tenderness of the bilateral thoracolumbar parspinals, decreased lumbar multifidus tone, hypermobility of thoracic (T) 11/12 vertebrae into extension, hypomobility of T10/ T11 vertebrae into extension, decreased bilateral scapulohumeral rhythm, fair bilateral LE balance, decreased bilateral LE strength, and decreased active lumbar range of motion. The patient's goals for physical therapy were to have decreased LBP with prolonged sitting and with playing soccer. The patient was cleared by her primary care physician to play soccer while wearing a soft back brace.

The patient received physical therapy at this clinic for the next 8 weeks. Physical therapy included patient education, balance and proprioception activities, posture and body mechanics training, strengthening, stretching, joint mobilization, core stability exercises soft-tissue mobilization, cold modalities, and electrical stimulation of the lumbar paraspinals. The patient frequently demonstrated improper form and decreased core stability while performing exercises; consequently, the patient required consistent supervision and verbal and tactile cueing during treatment.

After 8 weeks of physical therapy, the patient reported significant improvements in her subjective complaints and her doctor discharged her from physical therapy despite the therapist's recommendation to continue. Although the patient was being discharged, she continued to present with decreased LE and core strength which was limiting her ability to play soccer at full effort (Table 1). Also, the patient had participated in some dynamic strengthening activities, but it was evident that she would benefit from further plyometric and sport specific exercises in order to play soccer at one-hundred percent effort. The patient and her mother provided written and informed consent and the study was approved by the Midwestern University Institutional Review Board. The patient agreed to participate in a 6-week home exercise program (HEP) designed to help her continue strengthening her lower extremities, core, and scapular stabilizers. The patient's goals for her HEP were to have decreased LBP with sitting in class, sitting in the car, and while playing soccer.

Prior to being discharged with a HEP, the patient completed several outcome measures to assess her pain and current level of function. She reported her current pain to be a $4 / 10$ at its worst on an 11-point numeric pain rating scale (NPRS), as described by Childs et al., with 0 meaning "no pain" and 10 meaning "worst pain imaginable" [6]. The NPRS has been shown responsive in patients with LBP. Studies have indicated that a 2-point change on the NPRS is necessary to demonstrate a clinically meaningful change in LBP [6]. Disability related to her current condition was measured using the Modified Oswestry Low Back Pain Disability Questionnaire (OSW) [3]. The OSW is a self-report questionnaire designed to assess how LBP affects an individual's ability to manage in everyday life [3]. The questionnaire consists of 10 specific functional elements: pain intensity, person care, lifting, walking, sitting, standing, sleeping, social activity, travel, and employment/homemaking [3]. Each item is scored from 0 to 5 , with higher scores indicating greater disability [3]. The OSW has shown to be a reliable (Intra-class correlation of coefficient [ICC] of 0.90) and responsive (an area under the curve of 0.94) questionnaire [3]. Studies have also established the Minimal Clinical Important Difference (MCID) to be six points [3]. However, the OSW has yet to be validated in young athletes [7]. The patient's initial score was 18 out of 50 .

\section{Physical examination}

At her discharge appointment, the patient's strength, lumbar range of motion, and athletic performance was assessed. Lumbar active range of motion (AROM) for flexion, extension, and side 
Table 1: Manual Muscle Testing Measurements at Discharge Appointment and 7 week follow up appointment.

\begin{tabular}{|c|c|c|c|c|}
\hline & Left Side at Discharge & $\begin{array}{l}\text { Left Side at } 7 \text { week } \\
\text { Follow Up }\end{array}$ & Right Side at Discharge & Right at 7 week Follow Up \\
\hline Hip Flexion & $4+/ 5$ & $4+/ 5$ & $4+/ 5$ & $4+/ 5$ \\
\hline Hip Extension & $4+/ 5$ & $4+/ 5$ & $4+/ 5$ & $4+/ 5$ \\
\hline Hip Abduction & $4-/ 5$ & $4 / 5$ & $4-/ 5$ & $4 / 5$ \\
\hline Knee Flexion & $4+/ 5$ & $4+/ 5$ & $4+/ 5$ & $5 / 5$ \\
\hline Knee Extension & $5 / 5$ & $5 / 5$ & $5 / 5$ & $5 / 5$ \\
\hline Plantar Flexion & $4 / 5$ & $5 / 5$ & $4 / 5$ & $5 / 5$ \\
\hline Dorsiflexion & $5 / 5$ & $5 / 5$ & $5 / 5$ & $5 / 5$ \\
\hline Ankle Inversion & $4+/ 5$ & $4+/ 5$ & $4+/ 5$ & $4+/ 5$ \\
\hline Ankle Eversion & $4 / 5$ & $4+/ 5$ & $4+/ 5$ & $4+/ 5$ \\
\hline Shoulder Flexion & $4 / 5$ & $4 / 5$ & $4 / 5$ & $4+/ 5$ \\
\hline Shoulder Extension & $4 / 5$ & $4 / 5$ & $4 / 5$ & $4+/ 5$ \\
\hline Elbow Flexion & $4+/ 5$ & $4+/ 5$ & $4+/ 5$ & $4+/ 5$ \\
\hline Elbow Extension & $5 / 5$ & $5 / 5$ & $4+/ 5$ & $5 / 5$ \\
\hline Scapular Adduction & $4 / 5$ & $4 / 5$ & $4-/ 5$ & $4 / 5$ \\
\hline Scapular Depression and Adduction & $4 / 5$ & $4 / 5$ & $4-/ 5$ & $4 / 5$ \\
\hline $\begin{array}{l}\text { Scapular Adduction and Downward } \\
\text { Rotation }\end{array}$ & $4+/ 5$ & $5 / 5$ & $4+/ 5$ & $5 / 5$ \\
\hline Trunk Extension & $3+/ 5$ & $4 / 5$ & $3+/ 5$ & $4 / 5$ \\
\hline Trunk Flexion & $4 / 5$ & $4+/ 5$ & $4 / 5$ & $4+/ 5$ \\
\hline
\end{tabular}

bending was assessed using the dual inclinometer (DI) approach as recommended by the American Medical Association (AMA)'s Guide to The Evaluation of Permanent Impairment, $6^{\text {th }}$ Edition [8]. This standardized technique has been proved to correlate well with measurements taken from a radiograph for lumbar flexion $(\mathrm{r}=0.98)$ and moderately for lumbar extension $(r=0.75)$ [9]. This technique has moderate intra-rater reliability $(\mathrm{r}=0.71-0.90)$ and poor inter-rater reliability $(\mathrm{r}=.35-0.67)$ in adults with chronic LBP [10]. The patient's lumbar AROM was within normal limits according to published norms and did not cause the patient any pain (Table 2).

Lower extremity, upper extremity, and core strength was assessed using the standardized manual muscle techniques as described by Kendall and McCreary [11]. Manual muscle testing (MMT) has a high level of agreement based on $+/$ - one full grade, ranging between $82 \%$ and $97 \%$ agreement for inter-rater reliability and between $96 \%$ and $98 \%$ agreement for test-retest reliability [12]. Upon examination, the patient demonstrated weaknesses in hip abduction, ankle plantar flexion, scapular stabilization, trunk flexion, and trunk extension (Table 1).

Functional outcomes were also measured at the discharge appointment. The patient's agility was tested using the Agility $T$-Test, according to the original guidelines outlined by Semenick, which includes one practice trial and three timed trials [13]. The Agility $T$-test is a sports performance test that simulates joint-loading forces and kinematics that occur functionally and assesses the ability of an athlete to change direction, accelerate, and decelerate [14]. The test consists of a series of sprints between 4 cones. The participant begins at the starting cone and sprints forward 10 yards to touch the center (first) cone, shuffles left 5 yards to touch the second cone with their left hand, shuffles right 10 yards to touch the third cone with their right hand, shuffles back to the left 5 yards to touch the center (first) cone with their left hand, and then backpedals 10 yards to the starting cone to complete the test. The Agility $T$-test has been shown to be sensitive to changes in training patterns and differences in athletic skill levels $[15,16]$. It has also been reported that the Agility $T$-test has high between session reliability $(\mathrm{ICC}=0.96)$ in women [14]. However, studies on the reliability of the Agility $T$-test have been based on healthy, college-aged athletes; there have yet to be published studies on the use of or reliability of the Agility $T$-test in young athletes or people with LBP. At discharge, the patient completed one practice and three timed trials of the Agility $T$-test. She took 19.7 seconds, 18.2 seconds, and 15.0 seconds, respectively, to complete the test (Table 3).

Table 2: Lumbar Spine Active Range of Motion.

\begin{tabular}{l|l|l} 
Lumbar AROM Initial Measurement & Discharge Measurement
\end{tabular}

\begin{tabular}{|c|c|c|}
\hline Flexion & 10 degrees & 60 degrees \\
\hline Extension & 20 degrees & 22 degrees \\
\hline Right Sidebending & 5 degrees & 32 degrees \\
\hline Left Sidebending & 10 degrees & 26 degrees \\
\hline
\end{tabular}

AROM = active range of motion. Measurement performed using dual inclinometer (DI) approach as described by the American Medical Association (AMA)'s Guide to The Evaluation of Permanent Impairment, $6^{\text {th }}$ Edition [8]. 
Table 3: Agility T-test Time Recordings at Discharge and at 7 Week Follow up Appointment.

\begin{tabular}{|c|c|c|}
\hline & Discharge & $\mathbf{7}$ Week Follow-Up \\
\hline Trial 1 & 19.7 seconds & 15.4 seconds \\
\hline Trial 2 & 18.2 seconds & 14.4 seconds \\
\hline Trial 3 & 15.0 seconds & 13.7 seconds \\
\hline Average & 17.6 seconds & 14.5 seconds \\
\hline
\end{tabular}

The patient's agility was tested using the Agility $T$-Test, according to the original guidelines outlined by Semenick [13]. The test consists of a timed sprint test between 4 cones; the participant begins at one cone and sprints forward 10 yards to touch the center cone, shuffles left 5 yards to touch the second cone with their left hand, shuffles right 10 yards to touch the third cone with their right hand, shuffles back to the left 5 yards to touch the center cone with their left hand, and then backpedals 10 yards to the starting cone [13].

Another functional outcome used in this study to measure the patient's sports performance was the Functional Movement Screen (FMS). The FMS was developed to screen basic movement patterns used in athletes to assess risk for injury based on the athlete's ability to perform certain movements with or without compensation as well as to detect movement asymmetries $[17,18]$. The FMS consists of a series of seven self-described physical activities (unloaded deep squat, hurdle step, in-line lunge, shoulder mobility, active straight leg raise, trunk stability push-up, and rotary stability). The patient's ability to complete each physical activity is subjectively analyzed and scored using a 4-point scale with specific characteristics listed for each score $(0=$ pain with the movement, $1=$ unable to perform movement pattern, $2=$ compensation present to complete movement pattern, $3=$ movement performed as described), for a maximal score of 21 points [19]. Each physical activity is completed until the subject reports any pain; at this point, the screen is terminated. The FMS has been described as an injury predictor in athletes because it tests fundamental movements that require flexibility, stability, balance, muscle strength, and coordination. An athlete who has difficulty completing these movements is at risk for injury because tissue imbalances or compensations may be present. In a study investigating whether or not the FMS can be used to predict injury in professional football players, a composite score below 14 out of 21 was found to predict serious injury, with a specificity of 0.91 and a sensitivity of 0.54 [20]. Another study investigating the validity of the FMS looked at 38 female collegiate athletes. This study also found that a composite score of less than 14 (as established by Kiesel et al. [20]) was significantly associated with injury $(\mathrm{p}=0.0496)$ with a specificity of 0.74 and a sensitivity of 0.58 [21]. Furthermore, the scoring procedure for the FMS has been reported to have a high inter-rater reliability (ICC $=0.74-1.0) \quad[17,18]$, a moderate to strong intra-rater reliability (ICC $=.754-0.91),[17,18]$ and moderate test-retest reliability (ICC $=0.6)[17,18]$. Studies investigating the reliability and validity of the FMS have largely involved collegiate athletes or other healthy young adults. However, studies have yet to evaluate the reliability or validity of the FMS in young athletes or people with LBP. At her discharge appointment, the patient in the current study was only able to complete 3 of 7 movement patterns on the FMS before experiencing LBP. She scored a 4 out of a possible 21 points on the FMS, which is indicative of an increased chance of injury [20]. It is important to note that the FMS was completed following lumbar AROM testing, manual muscle testing, and the Agility $T$-test. These previous tests may have aggravated the patient's symptoms, potentially causing pain early on during the FMS.

\section{Initial clinical impression}

At discharge, the patient presented with LBP, decreased LE strength, decreased core strength, and decreased scapular stabilization strength (Table 1). Additionally, she presented with difficulty completing all items of the FMS due to LBP. It was evident from these exam findings that her decreased LE strength, especially plantar flexion strength and hip extensor strength, was contributing to her inability to play soccer with one-hundred percent effort because she lacked the strength needed to have a strong push-off during running. In addition to her decreased LE strength, the patient also presented with significant trunk flexion and extension weaknesses. These decreases in core stability were limiting her ability to stabilize her lumbar spine and pelvis during more advanced athletic skills, such as those included in the FMS, resulting in her LBP. Finally, the patient's decreased scapular stabilizer strength was contributing to her poor posture, increasing the strain on her thoracic and lumbar spine when sitting for prolonged periods of time.

Given her strength limitations, it was evident that the patient needed to continue strengthening her lower extremities and core in order to improve her ability to play soccer at a higher level of effort, improve her posture during prolonged periods of sitting, and decrease her LBP. Because 6 to 12 weeks of strengthening is typically needed to observe a significant increase in muscle strength, the patient was given a HEP to be completed 3 times a week for 6 weeks [22]. She was encouraged to return to the clinic after 6 weeks of completing the HEP to assess her progress and update her HEP as needed. The patient's prognosis for treatment was good given that she was familiar with the exercises she needed to perform at home.

Initial physical therapy intervention: Initial intervention included a HEP to continue strengthening the patient's abdominals, lower extremities, and scapular stabilizing muscles (Table 4). Due to the patient's tendency to perform exercises with poor form, it was important that the exercises chosen for her HEP were familiar. The exercises needed to be those she could perform correctly without tactile or verbal cues. Before being discharged to a HEP, the patient demonstrated each exercise to the physical therapy student in order to ensure that she was able to complete the exercise properly without compensations. The exercises were aimed to help improve her core stability in order to decrease strain on her lumbar spine, increase LE strength to help improve her soccer performance, and increase scapular stability to help improve her kyphotic posture. High impact, plyometric, and sports specific exercises were not added to the patient's initial HEP because she was still experiencing some LBP. The patient was provided with pictures and detailed instructions for each exercise. She was also provided a chart that she could use to check off her exercises as they were performed each week. The patient was asked to return to the physical therapy clinic after 6 weeks for a reevaluation and to update her HEP.

Physical therapy outcomes: The patient in this case was managed 
Table 4: First Home Exercise Program Given to Patient.

\begin{tabular}{|c|c|c|c|}
\hline Exercise & Description & Rationale & Sets $\mathrm{x}$ Repetitions \\
\hline $\begin{array}{c}\text { Single Leg Calf Raise on 8-in Step (each } \\
\text { leg) }\end{array}$ & $\begin{array}{l}\text { Patient slowly raises and lowers herself } \\
\text { on one foot on the edge of a step }\end{array}$ & $\begin{array}{l}\text { - Improve plantar flexor strength for } \\
\text { push-off during running gait }\end{array}$ & $3 \times 15$ per leg \\
\hline $\begin{array}{c}\text { Single Leg Balance with 3-Way Kick } \\
\text { (each leg) }\end{array}$ & $\begin{array}{c}\text { Patient stands on one leg; while } \\
\text { maintaining this position, she slowly kicks } \\
\text { her opposite leg into flexion, abduction, } \\
\text { and then extension to complete one } \\
\text { repetition. }\end{array}$ & $\begin{array}{l}\text { - Increase gluteus medius strength on } \\
\text { stance leg } \\
\text { - Engage core muscles to maintain } \\
\text { balance during dynamic activity }\end{array}$ & $3 \times 10$ per leg \\
\hline Rows, Green Thera-band & $\begin{array}{c}\text { Holding an elastic band secured to a door } \\
\text { handle, patient instructed bend elbows } \\
\text { and draw elastic band backwards while } \\
\text { pulling shoulder blades inferiorly and } \\
\text { medially. }\end{array}$ & $\begin{array}{l}\text {-Improve scapular strength/stabilization } \\
\text { to improve scapulohumeral rhythm and } \\
\text { decrease kyphotic posture. }\end{array}$ & $3 \times 10$ \\
\hline $\begin{array}{l}\text { Quadruped upper extremity shoulder } \\
\text { flexion and lower extremity hip extension }\end{array}$ & $\begin{array}{c}\text { Patient in quadruped and instructed } \\
\text { to perform abdominal bracing while } \\
\text { simultaneously lifting opposite upper and } \\
\text { lower extremity, holding the position for } 5 \\
\text { seconds before lowering }\end{array}$ & $\begin{array}{c}\text { - Increase core stability by strengthening } \\
\text { mulitifidus muscle, hip extensors, and } \\
\text { abdominals. }\end{array}$ & $3 \times 5$ per leg/arm \\
\hline Forward Lunge (each leg) & $\begin{array}{l}\text { Patient instructed to step forward into } \\
\text { a lunge position, keeping her forward } \\
\text { knee in correct alignment. She was then } \\
\text { instructed to push off her front leg to } \\
\text { return to the starting position }\end{array}$ & -Increase lower extremity strength & $3 \times 10$ per leg \\
\hline $\begin{array}{l}\text { Wall Squat with sustained shoulder } \\
\text { flexion }\end{array}$ & $\begin{array}{l}\text { Patient instructed to lean against a wall } \\
\text { with arms flexed above head. Patient } \\
\text { instructed to slowly lower down to } 90 \\
\text { degrees of knee flexion, hold for } 2 \\
\text { seconds, and raise up to starting position }\end{array}$ & $\begin{array}{l}\text {-Increase lower extremity strength } \\
\text {-Exercise models the unloaded deep } \\
\text { squat exercise on the FMS }\end{array}$ & $3 \times 10$ \\
\hline Supine March & $\begin{array}{l}\text { Patient in hook lying and instructed } \\
\text { to perform abdominal bracing while } \\
\text { marching lower extremities }\end{array}$ & $\begin{array}{l}\text {-Increase core stability to support } \\
\text { lumbar spine }\end{array}$ & $3 \times 45$ seconds \\
\hline
\end{tabular}

This HEP was prescribed for 6 weeks; it was actually performed by the patient for 7 weeks. The focus of this HEP was to increase core, LE, and scapular strength

with an initial HEPs (prescribed for 6 weeks, but not completed for 7 weeks) that, after re-evaluation, was progressed to a second HEP with more advanced, sports-specific activities (prescribed for an additional 6 weeks, but not completed). The patient was unable to keep her initial 6-week follow up visit and was instead re-evaluated after 7 weeks of performing her HEP; no reason was given for the delay in her return. At the 7-week follow up appointment, she reported that she had currently had no back pain, but rated her back pain as a 4/10 at its worst (NPRS). The patient also completed the OSW. Her score on the OSW at her follow up appointment was a 14/50. This score was not; however, significantly lower than her OSW score at discharge (18/50) given the MCID of 6 points 3. The patient also reported that she was continuing to play soccer and was also swimming.

That patient's lumbar AROM was not re-assessed at her follow up appointment secondary to the patient's subjective reports of no pain with lumbar AROM and the lack of AROM deficits at her discharge appointment. The patient's strength, agility, and sports performance were re-assessed. The FMS was performed first so that other tests and measures would not influence the patient's ability to complete the FMS. At her follow-up appointment, the patient was able to complete all 7 items on the FMS without LBP. Her composite score was an 11, which still placed her at increased risk for injury [20]. Her agility was then tested using the Agility $T$-test (Table 3 ) and her strength was re-assessed using MMT (Table 1). The patient demonstrated improvements in her average time to complete the Agility $T$-test (Table 3). She also demonstrated strength improvements in bilateral plantar flexion, bilateral hip abduction, bilateral scapular adduction, bilateral scapular depression and adduction, trunk extension, and trunk flexion (Table 1). Based on her progress, the patient received a new 6-week HEP that consisted of more sport-specific exercises to help her improve her agility and power in soccer (Table 5). The patient was asked to return to the clinic after 6 weeks to assess her progress and update her HEP.

The patient was contacted 5 weeks into her second HEP to schedule a follow-up appointment. The patient's mother reported that the patient was no longer complying with her HEP secondary to her increase in pain. Based on the patient's decreased compliance with her HEP secondary to her increased symptoms, the patient did not return for any further follow up appointments.

\section{Discussion}

The incidence of LBP due to Schmorl's nodes is low in adolescent athletes. However, physical therapists need to be aware of the signs, symptoms, and management of this condition for young athletes. In this case study, the patient presented with LBP and a diagnosis of Schmorl's nodes. Following 8 weeks of skilled physical therapy, 
Table 5: Second Home Exercise Program Given to Patient.

\begin{tabular}{|c|c|c|c|}
\hline Exercise & Description & Rational & Sets $\mathrm{x}$ Repetitions \\
\hline Forward and Lateral Double Leg Hops & $\begin{array}{l}\text { Patient instructed to tape a } 12 \text {-inch } \\
\text { line on floor and hop, on both legs, for } \\
30 \text { repetitions forward and backward } \\
\text { over the line, rest, and then hop } 30 \\
\text { repetitions laterally over the line. }\end{array}$ & \multirow{2}{*}{$\begin{array}{c}\text {-Increase lower extremity muscle } \\
\text { endurance and power by incorporating } \\
\text { plyometrics }\end{array}$} & $3 \times 30$ each direction \\
\hline Mountain Climber & $\begin{array}{l}\text { Patient in push-up position and } \\
\text { instructed to run in place, drawing } \\
\text { knees towards chest, maintaining a } \\
\text { neutral spine. }\end{array}$ & & $3 \times 20$ \\
\hline Step Matrix & $\begin{array}{l}\text { Patient in single leg stance; instructed } \\
\text { to slowly lower on stance leg and tap } \\
\text { opposite heal to ground at the 12:00 } \\
\text { position, raise back to starting position, } \\
\text { lower and tap opposite leg to the } \\
\text { side (3:00 position or 9:00 position, } \\
\text { depending on stance leg), return to } \\
\text { starting position, and then lower and tap } \\
\text { leg to the 6:00 position to complete one } \\
\text { repetition. }\end{array}$ & \multirow[t]{2}{*}{$\begin{array}{l}\text {-Increase lower extremity strength, } \\
\text { emphasizing gluteus medius strength } \\
\text { for pelvic stability }\end{array}$} & $3 \times 8$ per leg \\
\hline Side Steps with Theraband & $\begin{array}{l}\text { Patient instructed to secure an elastic } \\
\text { band around ankles and assume a } 1 / 4 \\
\text { squat position; while maintaining this } \\
\text { position, patient instructed to take side } \\
\text { steps, without allowing her trunk to } \\
\text { sway with each step. }\end{array}$ & & $3 \times 12$ steps per leg \\
\hline Supine Bracing with LE Bicycle kicks & $\begin{array}{l}\text { Patient in supine hooklying; patient } \\
\text { instructed to lift both feet off floor } \\
\text { and then straighten one leg; patient } \\
\text { instructed to alternate legs (like } \\
\text { pedaling a bike) while bracing } \\
\text { abdominal muscles in order to keep } \\
\text { lower back on floor. }\end{array}$ & -Increase core strength & $3 \times 10$ \\
\hline Plank & $\begin{array}{c}\text { Patient in plank position on elbows; } \\
\text { patient instructed to maintain a straight } \\
\text { back. }\end{array}$ & \multirow[b]{2}{*}{$\begin{array}{l}\text {-Increase scapular stabilizer strength } \\
\text { and core strength }\end{array}$} & $3 \times 45$ seconds \\
\hline Knee Push-Ups & $\begin{array}{l}\text { Patient in prone with knees bent; } \\
\text { patient instructed to push up, using } \\
\text { arms, to a modified push-up position. } \\
\text { Patient instructed to slowly lower back } \\
\text { to starting position while maintaining a } \\
\text { straight back. }\end{array}$ & & $3 \times 8$ \\
\hline
\end{tabular}

This HEP was prescribed for 6 weeks but was not completed by the patient. The focus of this HEP was to incorporate more sports specific exercises to further improve the patient's agility and power.

treatment then included a 7-week HEP designed to help the patient return to playing soccer with one-hundred percent effort. This treatment included strengthening exercises for the bilateral lower extremities, the core stabilizers, and the scapular stabilizers. The exercises were designed to improve the patient's core stability, decrease the strain on her lumbar spine, and allow her to play soccer at a greater intensity and with less back pain [23]. Following treatment, the patient presented with increased LE and core strength as well as improved performance on the Agility $T$-test and the FMS. However, the patient did not present with significant pain changes on the NPRS or the OSW.

Although the patient demonstrated some gains in strength and sports performance, her pain did not seem to change significantly following treatment. The patient's HEP included many basic core and LE exercises that were familiar to her in order to ensure that she performed the exercises with proper form. However, the patient may have demonstrated greater strength gains had the overload principle been applied to her strengthening exercises during treatment. The overload principle states that if muscle performance is to increase, a load that exceeds the muscles metabolic capacity must be applied [22]. To achieve overload, this exercise may have included additional resistance by having the patient hold dumbbells since her LE muscles could already lift and lower her body against gravity, given her LE strength was at least a 4/5 on MMT. Had additional resistance been applied to her other exercises as well, the patient may have demonstrated greater strength gains in all of the other muscle groups.

In order to address the patient's ongoing pain, her HEP could have included additional pain management techniques, such as stretching and the use of superficial heat. A randomized controlled study by Fanucchi et al. [24] demonstrated that an 8-week exercise program can reduce the intensity and prevalence of LBP in 12-13 year old children ( 72 children, mean age 12.3). One component of this program was iliopsoas, hamstring, and rectus femoris stretches [24]. Decreased hamstring and iliopsoas muscle length are considered 
physical risk factors for LBP because, during periods of rapid growth, muscles are often unable to keep pace with the rate of bone growth, causing muscle imbalances and decreased flexibility which leads to LBP $[2,24]$. At the three month follow up, significant betweengroup differences in favor of the experimental group were found in hamstring and iliopsoas muscle length [24]. Thus, the authors concluded that the increased muscle lengths found with the exercise contributed to the absolute risk reduction for LBP in the experimental group of $24 \%$ ( $95 \%$ CI 4 to 41 ) compared to that of the control group [24]. Given the results of Fancucchi et al. [24] the patient in this case report may have benefitted from hamstring and iliopsoas stretching exercises in her HEP to help decrease her LBP. Thus, an additional stretching program to maintain appropriate length in these muscles may have been adventitious.

Adding a superficial heat regimen to the patient's HEP may have also aided in decreasing the patient's pain. At initial evaluation, the patient presented with increased tone and tenderness in the thoracolumbar paraspinal muscles. Increased tone in paraspinal musculature may have been attributed to muscle guarding because of the nearby injury (the presence of Schmorl's nodes) or as a compensation for her weak core stability muscles. Superficial heat modalities convey heat by conduction and can elevate the temperature of muscle tissues $0.5 \mathrm{~cm}$ or less from the surface of the skin [25]. An increase in tissue temperature causes local vasodilation, which results in the decreased firing rate of alpha motor neurons, thus may decrease LBP due to muscle spasm [26]. A Cochrane review, conducted by French et al. found that there is moderate evidence to support the use of superficial heat for the treatment of chronic LBP. Adding superficial heat treatments to the patient's HEP may have helped decrease her pain temporarily, but not long term.

The results from this case report are consistent with many other studies concerning rehabilitation intervention plans for adolescents with LBP. A meta-analysis by Calvo-Muñoz, Gómez-Conesa, and Sánchez-Meca investigated whether physical therapy treatment is effective for LBP in children and adolescents. This meta-analysis included eight studies, consisting of 334 subjects, ages 11 to 18 , that used several outcome measures (pain, disability, flexibility, endurance, and mental health) to determine the effectiveness of different physical therapy interventions in the treatment of LBP in adolescents [27]. Interventions included exercise ( 2 studies), manual therapy (1 study), combined treatment of back education and therapeutic physical conditioning ( 1 study) and exercise combined with other treatments such as manual therapy, modalities, and education (7 studies) [27]. The results of this meta-analysis concluded that physical therapy is beneficial for the treatment of LBP in adolescents, and that the combination of physical exercise and manual therapy is most effective (predicted, estimated effect of 10.55) [27]. Given the findings of this meta-analysis, the treatment conducted in this case study may have been effective given that the HEP included physical conditioning exercises. However, the treatment might have been more effective at reducing the patient's pain had manual therapy been included. Unfortunately, due to the lack of an official referral to continue onsite physical therapy, the patient in this case study could not be seen for manual therapy by her physical therapist.
Although the patient's HEP did not include stretching exercises or manual therapy, many exercises utilized in her HEP have been shown to be effective at reducing LBP and in improving one's athletic performance. For example, the core stability exercises included in this HEP are effective in the management of LBP due to Schmorl's nodes.2 Core stability strength is especially important for soccer players, as it is the foundation of all limb movements, and controls the body's balance when imposed to internal and external perturbations during a soccer game [23]. Thus, poor core stability contributes to decreased dynamic balance, which increases a soccer player's risk for injury, especially LBP. The HEP in this case report included many core stability exercises, as well as LE strengthening exercises, aimed at increasing her balance, thus improving the patient's athletic ability and decreasing her risk for further LBP.

With regard to adherence to HEP, few studies have been conducted that examine an adolescent's compliance with HEPs for LBP. Previous studies have demonstrated that factors that positively influence adherence to HEP include history of participation in a previous HEP, HEPs with less than 6 exercises, self-efficacy of exercises, emotional support, and frequency and quality of the patient's interactions and communication with the physical therapist [28]. This communication includes clarifying doubts of patients, giving patient's information about their illness, explaining the need for the HEP, and giving clear instructions for each exercise in the HEP [28]. The patient in this case documented her adherence using pre-fabricated chart where she marked-off performing each exercise, 3 times per week, for the 7 weeks. Her high level of adherence may have been due to her previous experience in performing the exercises at previous physical therapy sessions. The patient also had strong emotional support from her parents, which may also have aided in her compliance. Despite the patient's adherence with her HEP, communication between the therapist and the patient could have been improved. For instance, had the physical therapist communicated with the patient after 3 or 4 weeks of the patient's HEP, the therapist might have found out that the patient's LBP had not yet improved. Given this information, the therapist could have re-assessed the patient sooner and could have added more pain-management techniques to the patient's HEP.

\section{Conclusion}

This case study suggests that adolescent athletes with LBP caused by Schmorl's nodes may be capable of adhering to a HEP if they are given familiar exercises, have appropriate verbal and visual instructions, and have additional emotional support. Furthermore, this case study suggests that basic LE and core strengthening exercises may have been effective at increasing LE and core strength as well as increasing one's speed, agility, and overall athletic performance. However, strengthening exercises alone may not always significantly reduce LBP. This study suggests that improvements in core strength and athletic performance do not necessarily coincide with decreases in LBP. These findings suggest that a HEP given to adolescent athletes with LBP, especially those with Schmorl's nodes, should also include stretching exercises, manual therapy, and the use of modalities like superficial heat to help decrease LBP.

It should be pointed out that this case report represents a low level of evidence for the use of a HEP for a young female with Schmorl's 
nodes and LBP. More randomized, clinical trials are needed to investigate the effectiveness of HEP for the treatment of LBP in adolescent athletes with Schmorl's nodes. These studies need to examine which therapeutic techniques are most effective for treating LBP caused by Schmorl's nodes, such as strengthening exercises, manual therapy, and the use of therapeutic modalities. Further research is also needed in regard to adolescent compliance with HEP and the use of the FMS and the Agility $T$-Test in adolescents athletes with LBP.

\section{References}

1. Le Gall F, Carling C, Reilly T (2008) Injuries in young elite female soccer players: an 8-season prospective study. Am J Sports Med 36: 276-284.

2. Purcell L, Micheli L (2009) Low back pain in young athletes. Sports Health1 212-222.

3. Fritz JM, Irrgang JJ (2001) A comparison of a modified Oswestry Low Back Pain Disability Questionnaire and the Quebec Back Pain Disability Scale. Phys Ther 81: 776-788.

4. DePalma MJ, Bhargava A (2006) Nonspondylolytic etiologies of lumbar pain in the young athlete. Curr Sports Med Rep 5: 44-49.

5. Standaert C (2008) Low back pain in the adolescent athlete. Phys Med Rehabil Clin N Am 19: 287-304, ix.

6. Childs JD, Piva SR, Fritz JM (2005) Responsiveness of the numeric pain rating scale in patients with low back pain. Spine (Phila Pa 1976) 30: 1331 1334.

7. d'Hemecourt PA, Gerbino PG 2nd, Micheli LJ (2000) Back injuries in the young athlete. Clin Sports Med 19: 663-679.

8. Association AM (2007) Guides to the Evaluation of Permanent Impairment, Sixth Edition. American Medical Association.

9. Saur PM, Ensink FB, Frese K, Seeger D, Hildebrandt J (1996) Lumbar range of motion: reliability and validity of the inclinometer technique in the clinical measurement of trunk flexibility. Spine (Phila Pa 1976) 21: 1332-1338

10. Nitschke JE, Nattrass CL, Disler PB, Chou MJ, Ooi KT (1999) Reliability of the American Medical Association guides' model for measuring spinal range of motion. Its implication for whole-person impairment rating. Spine (Phila Pa 1976) 24: 262-268

11. Kendall F, McCreary E, Provance P, Rodgers M, Romani W (2005) Muscles: Testing and Function, with Posture and Pain. Lippincott Williams \& Wilkins.

12. Cuthbert SC, Goodheart GJ Jr., (2007) On the reliability and validity of manual muscle testing: a literature review. Chiropractic \& Osteopathy 15: 4-4

13. Semenick D (1990) Tests and measurements: the t-test. Strength and Conditioning Journal 12: 36-37.

14. Munro AG, Herrington LC (2011) Between-session reliability of four hop tests and the agility T-test. J Strength Cond Res 25: 1470-1477.

15. Delextrat A, Cohen D (2008) Physiological testing of basketball players: toward a standard evaluation of anaerobic fitness. J Strength Cond Res 22 : 1066-1072.

16. Miller M, Herniman J (2006) The effects of a 6-week plyometric training program on agility. J Sports Sci Med 5: 459-465.

17. Smith CA, Chimera NJ, Wright NJ, Warren M (2013) Interrater and intrarater reliability of the functional movement screen. J Strength Cond Res 27: 982 987.

18. Gribble PA, Brigle J, Pietrosimone BG, Pfile KR, Webster KA (2013) Intrarater reliability of the functional movement screen. J Strength Cond Res 27: 978981.

19. Parchmann CJ, McBride JM (2011) Relationship between functiona movement screen and athletic performance. J Strength Cond Res 25: 33783384.

20. Kiesel K, Plisky PJ, Voight ML (2007) Can Serious Injury in Professional Football be Predicted by a Preseason Functional Movement Screen? N Am J Sports Phys Ther 2: 147-158.

21. Chorba RS, Chorba DJ, Bouillon LE, Overmyer CA, Landis JA (2010) Use of a functional movement screening tool to determine injury risk in female collegiate athletes. N Am J Sports Phys Ther 5: 47-54.

22. Kisner C, Colby LA (2007) Therapeutic Exercise: Foundations and Techniques. F.A. Davis Company.

23. Borghuis AJ, Lemmink KA, Hof AL (2011) Core muscle response times and postural reactions in soccer players and nonplayers. Med Sci Sports Exer 43: 108-114.

24. Fanucchi GL, Stewart A, Jordaan R, Becker P (2009) Exercise reduces the intensity and prevalence of low back pain in 12-13 year old children: a randomised trial. Aust J Physiother 55: 97-104.

25. French SD, Cameron M, Walker BF, Reggars JW, Esterman AJ (2006) A Cochrane review of superficial heat or cold for low back pain. Spine (Phila $\mathrm{Pa}$ 1976) 31: 998-1006.

26. Cameron M (2003) Physical Agents in Rehabilitation: From Research to Practice. 2nd ed. St. Louis, MO: Elsevier Science.

27. Calvo-Muñoz I, Gómez-Conesa A, Sánchez-Meca J (2013) Physical therapy treatments for low back pain in children and adolescents: a meta-analysis. BMC Musculoskelet Disord14: 55-55.

28. Medina-Mirapeix F, Escolar-Reina P, Gascón-Cánovas JJ, Montilla-Herrador J, Jimeno-Serrano FJ, et al. (2009) Predictive factors of adherence to frequency and duration components in home exercise programs for neck and low back pain: an observational study. BMC Musculoskelet Disord10:155-155.

Copyright: (c) 2014 Evans CC, et al. This is an open-access article distributed under the terms of the Creative Commons Attribution License, which permits unrestricted use, distribution, and reproduction in any medium, provided the original author and source are credited. 